\section{DEBTS, POVERTY AND JUSTICE}

\section{CRISTIAN DIMITRIU ${ }^{1}$}

(UBA, Argentina)

\begin{abstract}
In this article, I make the idea that poverty outcomes are not necessarily morally relevant for assessing policies as clear as possible by discussing a specific case within the global justice debate: sovereign debts. The outcome view that I attack has mainly been represented by Pogge, who has argued that the international lending system is unjust because, under it, there is massive and avoidable poverty . The competing view that I propose is deontological: the lending system is not unjust because of its consequences on poverty, but because it allows and promotes (morally) non-binding debts.
\end{abstract}

Keywords: International Lending; Poverty; Outcomes; Pogge; Bindingness

It is usually thought that if a policy generates poverty, that policy is unjust. Thus, we should evaluate policies by measuring poverty that results from them. If, say, a government decides to change the rules for having access to health benefits, and it turns out that more people will fall below the poverty line as a result of this new rule, the new rule will be considered unjust on this thought. The same kind of idea is common in the context of global justice debates.

It is clear, however, that poverty creation is neither a necessary nor a sufficient condition for a policy to be unjust. It might well be the case that a policy generates poverty and it is still perfectly acceptable and, conversely, it might be the case that a policy does not generate poverty (and, in fact, even improves the situation of most people) but it is totally unjust. Reducing funding to health care temporarily can be acceptable on the ground that such reduction is necessary to prevent even bigger problems, such as massive inflation; and improving health benefits for the poor can be unacceptable if the funds are obtained by reducing the budget for even poorer groups of the population. Despite the fact that outcomes are conceptually detached from the justice/injustice of a policy, we still want to say that some policies are just or unjust, and that there are good reasons for believing that they are. 
In this article, I make the idea that poverty outcomes are not necessarily morally relevant for assessing policies as clear as possible by discussing a specific case within the global justice debate: sovereign debts. The claim I would like to defend is that generating poverty among the population of a poor state as a result of a loan is independent from the fact that such debt is morally binding. People might become poorer as a result of a loan, and the loan might still be binding; and people might not be negatively affected as a result of a loan, and the loan might be non-binding. It is of course often the case that there is something wrong with lending that generates massive poverty. However, in my view, the fact that lending and poverty exist parallel to each other is not what makes a loan binding or non-binding. Thus, it is misguided to measure poverty as a way of testing the bindingness of a debt.

I will proceed as follows. First, I will explain in some detail Pogge's view about lending and justice, as he is the main defender of the outcome-view that I am trying to refute. Second, I will show two possible worries about Pogge's view. I will call the first one the "agnosticism objection" and the second one the "normative limitation objection". Third, I will briefly describe my own account of the conditions under which lending would count as non-binding. This account does not necessarily rely on outcomes.

\section{Pogge's outcome-view}

An important aspect of Pogge's project throughout his writings is to show that explanatory nationalism is wrong. Explanatory nationalism is the view that the reasons why countries fail are almost always local, instead of global. These local causes usually include bad decisions made by politicians, corruption, authoritarianism, etc. According to explanatory nationalism, international practices, rules and power have a minor, or non-existing, role in explaining poverty within nations. Pogge shows that explanatory nationalism is misleading by showing how the global order contributes, or causes, poverty. He does not deny that domestic factors play a role in poverty creation. But he believes that explanatory nationalists clearly minimized the impact that the global order has on domestic poverty.

An additional important thesis that Pogge defends is that with minor changes in international rules and practices, most of the global poverty problem could be eliminated. These small modifications, according to Pogge, would entail only a small reduction of the income of the affluent. Following Cohen, we can call this thesis the "strong thesis" 2 . 
The upshot of Pogge's analysis is that the global order is unjust, because it causes or helps to sustain poverty in the world and, additionally, because this harm can be prevented by making small modifications to the rules. Notice that for him the injustice of the global order is grounded on an outcome: the global order is unjust because it generates suboptimal outcomes ${ }^{3}$.

How does international lending fit within this account? The way the international lending system works is a crucial example in support of the argument that explanatory nationalism is wrong, and in support of the strong thesis. Thus, for Pogge, the international lending system is unjust. Let us consider this argument in more detail. A central feature of the current international order is that all kinds of governments- no matter how brutal or corrupt they are-are entitled to borrow money in the name of the state they represent. Pogge calls this entitlement the "borrowing privilege". Because of the existence of the borrowing privilege, Pogge says, millions of people have impoverished or worsened their situation. Had this privilege not existed, or if we implement some (minor) modifications to the rules that govern lending, the situation of the poor would be substantially better.

Thus, for Pogge, the injustice of the borrowing privilege lies mainly on the fact that it has negative effects on the population, and that these effects could have been reverted by implementing some minor modifications to the rules. Pogge therefore grounds the injustice of the lending rules on the outcome they generate. This becomes clear in the following quotes:

[...] the existing world order is itself a crucial causal factor in the prevalence of corruption and oppression in the poor countries.

The borrowing privilege we confer upon a group in power includes the power to impose internationally valid legal obligations upon the country at large. Any successor government that refuses to honor debts incurred by an ever so corrupt, brutal, undemocratic, unconstitutional, repressive, unpopular predecessor will be severely punished by the banks and governments of other countries. At minimum it will lose its own borrowing privilege by being excluded from the international financial markets. Such refusals are therefore quite rare, as governments, even when newly elected after a dramatic break with the past, are compelled to pay the debts of their ever so awful predecessors.

The international borrowing privilege makes three important contributions to the incidence of oppressive and corrupt elites in the developing world. First, this privilege facilitates borrowing by destructive rulers who can borrow more money and can do so more cheaply than they could do if they alone, rather than the whole country, were obliged to repay. In this way, the borrowing privilege helps such rulers maintain themselves in power even against near-universal popular discontent and opposition. Second, the international borrowing privilege imposes upon democratic successor regimes the often huge debts of their corrupt predecessors. It thereby saps the capacity of such democratic governments to implement structural reforms and other political 
programs, thus rendering such governments less successful and less stable than they would otherwise be. Third, the international borrowing privilege strengthens incentives toward coup attempts: Whoever succeeds in bringing a preponderance of the means of coercion under his control gets the borrowing privilege as an additional reward ${ }^{4}$.

As we can see, Pogge clearly connects the borrowing privilege with its effect in order to condemn it. The specific effects he has in mind are incentives for corrupt governments to stay in power, incentives to get to power through violent means, and hindering the ability of future generations to develop as they would like. The view that the borrowing privilege is unjust in light of the effects it has on the population has been consistent throughout Pogge's writings. In a different article, Pogge says that the borrowing privilege (along with the resource privilege),

[...] confer upon a group in power "the power to effect legally valid transfers of ownership rights in such resources" and "to impose internationally valid legal obligations [of paying back debts made, for example, by a dictatorial regime] upon the country at large" (2004, 270-71). Pogge rightly says that these privileges "provide strong incentives to potential predators (military officers, most frequently) to take power by force" and to oppress their people and divert state revenues into their own pockets $(2005 \mathrm{a}, 49)$. Moreover, with tax laws the rich countries have contributed to the bribery of elites in poor countries, and by insisting "on continued and asymmetrical protections of their markets through tariffs, quotas, anti-dumping duties, export credits, and subsidies to domestic producers, greatly impairing the export opportunities of even the very poorest countries [...] these protections certainly account for a sizeable fraction of the 270 million poverty deaths since $1989 . " 5$

And finally, in a different text, Pogge states that,

Unconditional international resource and borrowing privileges are also highly advantageous to many a putschist or tyrant in the poor countries, for whom they secure the funds he needs to maintain himself in power even against the will of a large majority of his compatriots. Such privileges are, however, an unmitigated disaster for the global poor who are being dispossessed through loan and resource agreements over which they have no say and from which they do not benefit ${ }^{6}$.

Again, the central point here is that the borrowing privilege is wrong because of the effects it has on the population (in this specific paragraph, the effects would be the dispossession or the lack of benefit). 


\section{Two possible worries about Pogge's approach: the agnosticism thesis and the normative limitation thesis}

So far, I have described the main features of Pogge's view. This view, however, is vulnerable to two different objections. Since these objections seem to be effective, it is better, I believe, to abandon Pogge's strategy altogether, and discuss the morality of debts under a new perspective (which I will describe briefly in the third section). I will discuss each of these two objections in turn.

\section{(a) The agnosticism objection}

I borrow the agnosticism objection from Cohen ${ }^{7}$. Cohen assumed that Pogge's approach is the correct one (that is, he seems to accept the view that we can assess the morality of the lending system by evaluating its impact on the quality of life of the population). However, given the fact that it is difficult, if not impossible, to precisely calculate what would happen if the borrowing privilege did not exist, he says, there are just not enough reasons to reject the borrowing privilege. Perhaps the absence of the borrowing privilege would increase poverty, but perhaps it would decrease it. Estimating the exact implications of the borrowing privilege is difficult because it involves relying on counterfactuals (that is, it involves estimating what would happen if the borrowing privilege did not exist), and it is of course very difficult to speculate how alternative scenarios might come about. The agnosticism objection thus holds that we cannot judge the morality of loan transactions by relying on an analysis of their impact.

Cohen reaches the conclusion that Pogge's position on lending leads to agnosticism by carefully reconstructing his position. As said earlier, Pogge has what Cohen calls a Strong Thesis. On the Strong Thesis "most of the global poverty problem could be eliminated through minor modifications in the global order that would entail at most slight reductions in the income

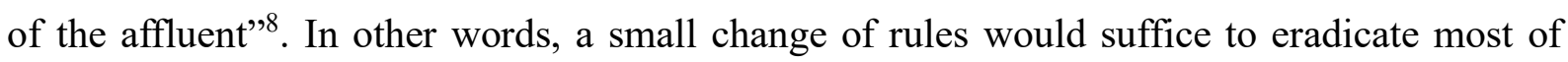
world poverty.

In particular, for the case of debts, alternative rules on debt repayment might create 
incentives not to lend, at least in some case. The alternative rules can come about, for example, if the international community introduces an ex ante announcement that certain governments are not authorized to borrow (which would be accompanied with a requirement not to lend to them). Supposedly, this incentive not to lend would have a positive impact on the global poor, as autocratic governments will have smaller returns and incentives to stay and power, and institutional changes within those countries will be more likely. The idea of introducing an ex ante requirement has been introduced not only by Pogge, but also by other scholars ${ }^{9}$.

Now, the main problem with Pogge's view, Cohen says, is that we cannot know what exactly would happen if we "slightly" change a rule. Similarly, for the case of lending, we cannot know what exactly the consequences of "slightly" modifying the rules of international lending are. The impact on poverty might in fact be positive, but it might also be negative or neutral. This is especially true if also domestic factors explain poverty, which is usually the case. Suppose that loans to autocratic governments are blocked, as Pogge suggests. If an autocratic government is overall benefitting the society - in which case it would be a benevolent dictatorship - the rule to block loans to autocratic governments would harm, rather than benefit, the people. Suppose, further, that a good/legitimate/democratic government borrows money, and their policies, due to incompetence or corruption, lead to more poverty. The "slight" modification of the rule would not block loans to these societies and, as a consequence, it would not prevent poverty creation. Moreover, since the modified rule proposes to block loans to autocratic governments, it is very likely that more funds would be diverted to democratic (but inept or corrupt) governments, in which case the rule would have the unwanted consequence that it would end up creating more poverty than the poverty it would be avoiding. In sum, as Cohen says, "the relationship between an odious debt doctrine that appropriately limits the subsequent burdens and claims about alleviating extreme poverty is tenuous, both because so much extreme poverty is untouched by issues about borrowing privileges, and because the implications for poverty alleviation of changing those rules is so uncertain." ${ }^{10}$ And in a different part of the text, "an argument of this brevity (referring to the Strong Thesis) is insufficient for any empirical thesis worth exploring. It falls well short of what is needed for an ambitious claim about the impact of one part of a complex social economic order on another part"..."there is a large gap between might explain and does explain: between noting that a global-based rulebased explanation of most extreme poverty can coexist with explanations focused on domestic conditions and showing that current global rules do contribute substantially to variations in domestic poverty. That gap simply cannot be filled in a few pages. Social science is not that 
easy."11

In a nutshell, the problem that Cohen sees with Pogge's view is that he makes conclusions about the morality of the global order by relying on empirical claims, and these claims are hard to support. It is a task of social science to support them, and social science has not done this so far. Because of the improbability of the strong thesis, Cohen concludes that Pogge's view that the global order harms the poor is weak.

Cohen makes an excellent point. However, he also falls prey of this objection, as he seems to assume that if we knew the exact consequences of the lending rules, and if these consequences were harmful for the poor, then we should conclude that the lending system is unjust. In other words, he also seems to assume that we can discuss the morality of policies by studying their impact on poverty. I believe, however, that it is tricky to reach normative conclusions from empirical facts, as the normative and the empirical domain are conceptually independent from each other. This leads us to the second objection: the normative limitation.

\section{(b) Normative limitation of the argument}

The normative limitation of Pogge's argument - a limitation that Cohen also has - is that he assumes that it is plausible to extract a normative conclusion from empirical information. This step, however, is unwarranted. Even if we knew the exact empirical outcomes of policies $\mathrm{X}$ or $\mathrm{Y}$, and even if we knew with certainty that these outcomes make people worse off, this would not be enough to morally condemn policy $\mathrm{X}$. This is because an action that makes an agent or a group of agents worse off does not necessarily wrong this agent or group of agents. In other words, making someone worse off and wronging her are conceptually independent from each other. It is possible to imagine that someone who is harmed (i.e. made worse off) is not wronged, and that someone who is wronged is not harmed. For example, a few years ago Argentina devaluated its currency to promote exports of soy. This benefitted local farmers, but harmed farmers in the Midwest of the US. Although there was clearly a harm in this case, we do not tend to believe that Argentina wronged the farmers of the Midwest. We rather tend to think that Argentina, and states in general, have autonomy to freely determine the value of their currency, and that eventually those who are affected by this new value will have to adapt to the new scenario. Needless to say, this does not mean that states have autonomy to do anything they want. However, changing the value of the currency is something that is certainly within 
the legitimate purview of states. Cosmopolitans or statist do not disagree with this basic intuition. Except for an extreme version of these two views, cosmopolitans and statists have in general agreed that global duties to the poor are compatible with some degree of autonomy or self-determination of states $^{12}$, meaning by this that, under certain conditions, states can and should give their citizens priority.

On the other hand, it is possible to imagine that an agent can wrong someone, without making him worse off. Consider, for example, the case social groups who benefit from other groups who have been victimized in the past. They do not cause or create the harm, but they benefit from it. Therefore, they wrong but do not harm.

For the specific case of debts, rules of lending can make people worse off, and they would not necessarily wrong them for that reason; and rules of lending that do not make people worse off can nonetheless be wrongful. To illustrate, let us consider a loan transaction between individuals in the domestic realm. B borrows money from A in the name of C. B is an authorized agent of $\mathrm{A}$ (that is, $\mathrm{B}$ is authorized by $\mathrm{C}$ to borrow in her name; and is also authorized to use the money in the name of C). As a result of the loan, $\mathrm{C}$ becomes poorer. This can happen because A makes poor decisions about the money, or because the situation of $\mathrm{C}$ changes and the debt ends up being more burdensome than expected. In this case, although $\mathrm{C}$ becomes worse off as a result of the transaction, $\mathrm{C}$ has been made worse off, but not wronged. For the international domain, a public official can borrow in the name of the state, and the people living within that state can become worse off as a result of the loan. However, as in the case of the private transaction, this would not mean that the state or that the people living within that state have been wronged. It could simply mean that the government unknowingly used the money in a way that ended up being against the interest of the state, and that the state becomes poorer as result of this. These examples show that it is conceptually possible to make an agent worse off, without harming her. Conversely, we can imagine that B borrows money in the name of A, B is not authorized to borrow for a specific purpose, but borrows anyway. The loan might not necessarily harm or make A worse off. However, A has been wronged, because someone made an unauthorized decision in his name. Something similar can be said about states. If a government borrows money and uses it for corrupt unauthorized purposes (such as for example building a palace for one of the officials), we might say that the loan itself did not necessarily make the people worse off. In fact, it might have even benefitted them by generating some jobs or income for the local population. In any case, the point of showing that wronging someone and making her worse off are conceptually different is to highlight the fact that both Cohen and 
Pogge are mistaken in defending the claim that we can morally assess the rules of lending by looking at their empirical consequences. The claim is not mistaken because it is difficult to calculate the empirical consequences of policy, or because we lack sufficient information, but because of the normative limitation that they overlook: the empirical consequences of a policy are possibly irrelevant to determine the morality of that policy.

So Pogge's claim that the global order, through its lending rules (among other components) is harming the poor might be correct, but this does not necessarily imply that such harm constitutes a wrong. In order to show that there is a wrong involved, the argument requires more than a simple empirical analysis. In fact, it should incorporate additional normative considerations, so that it can show that a wrong has been inflicted. Such additional normative considerations can be, for example, that lending rules should be changed on the ground that they involve complicity with unacceptable regimes. This is an argument that Nili makes, when he says, with respect to the borrowing privilege and the resource curse, that "the idea is that we need to stop our material complicity in crime for the sake of our own moral integrity, independently of any prospects for improved outcome for others." ${ }^{\text {"13 }}$ Another possible normative consideration is that there is a human rights threshold that people are entitled to, and the lending system is forcing people below this threshold. Pogge seems to defend this view, but he does not make it explicit in connection with the lending rules ${ }^{14}$. Pogge does not provide these additional normative premises, and simply assumes that what makes lending system problematic is that it leads to a certain outcome that he finds undesirable.

\section{Conditions for non-bindingness of debts}

The discussion so far suggests that there are alternative ways of assessing the morality of the lending system. These alternative ways do not make an assessment in terms of the impact or outcome that lending rules generate. Rather, they focus on the structure of the agreement that generated the debt. Let us consider the following example at the level of private transactions to make this clear. A CEO borrows money from a bank in the name of the corporation for which it works. Afterwards, the CEO uses the funds for purposes for which he is not authorized (e.g. instead of using the money for the purposes of advancing the interests of the company, he buys a nice present to his daughter). The lender knows, before lending, that the CEO will use the money for these non-authorized purposes. Clearly, the corporation is not on the hook for these 
debts. We can think of a similar structure for the case of sovereign debts. The government of a country borrows money in the name of the state. This government uses the money for purposes for which it is not authorized (for example, to build a private airport for one of the officials of that government). The lender (for example the IMF) knows that the officials who borrowed the money will misuse the funds, but lend anyway. Clearly, the state is not on the hook for the debt. Why would the state (and therefore the population) bear the burden of a debt that they did not authorize?

In both cases what makes the debt immoral (or non-binding) is not the fact that it generated poverty, or that it made one of the parties worse off. These things seem to be rather irrelevant. Rather, what makes them non-binding is that one the agents made a decision in the name of a third party without proper authorization.

This comparison requires us to be a bit more specific about what exactly makes a debt non-binding. A state can declare a debt non-binding when basically two conditions are satisfied ${ }^{15}$. The first condition is that the public official of a state oversteps his authority as public official, and uses borrowed funds for purposes for which he is clearly and obviously not authorized. We can call this the authorization condition. If a public official satisfies the authorization condition, he can no longer be consider to be entitled to bind the state he represents, for he does not have authority to borrow for those purposes in the first place. Notice that the issue here is not whether the public official is authorized to rule (this seems to be irrelevant to determine the odiousness of a debt), but whether the public official is authorized to spend the money for those specific purposes. Now, one might argue here that the authorization condition is too vague, because there is always disagreement about what counts as spending borrowed funds in accordance with non-authorized funds. Some people believe that a public official is overstepping his authority if he bailouts private companies in times of crisis, and others believe that he is overstepping his authority if he uses public funds to provide healthcare to the poor (as some libertarians would think). In order to respond to this objection, we can be clearer in defining the authorization condition. The decision to spend the money by a public official in a certain way would count as non-authorized if there is no possible reasonable disagreement about the fact that it is non-authorized. People from all kinds of philosophical and political conceptions would agree that a public official cannot spend money to violate the basic human rights of the population of the state he represents, or that he cannot spend public funds for his own personal interest (such as buying himself expensive horses). The underlying reason why they would consider that the agent has authority to do certain things is 
precisely because people delegated him authority for those things; and it would be implausible to argue that they would delegate authority to someone, so that this person violate their basic human rights, or embezzles their entrusted funds. A second condition under which a sovereign loan is non-binding is that lenders are aware, or should have been aware, of the possible misuse of funds by the public officials. This condition would rule out potential arguments by the lenders that since they lent in good faith, and therefore did not know that the money was going to be misused, they are entitled to receiving back the full amount of the debt. We can call this the due diligence condition. This condition is satisfied when there are visible indications that a public official who borrows money will use it for non-authorized purposes. This happens when they have a clear record of corruption or oppression, or when there is something suspicious in the transaction itself. If the president of a state asks for money to build up an airport in his private residence, the chances that the transaction involve corruption are very high, even if this president has a clean record. The lender is on notice, and the good faith condition would be satisfied. When the authorization condition and the good faith condition are both simultaneously satisfied (i.e. when public officials use borrowed funds for non-authorized purposes, and the lenders knew or should have known about this), a debt is odious, and we should not consider it a state debt. If only the first condition is satisfied, the debt can also arguably be considered odious, but the case seems weaker. If only the second condition is satisfied, the debt will definitely not be non-binding, because even if there is something suspicious about the loan before it happens, the state will be bound if the money is spent in accordance with acceptable public purposes (such as for example building public roads or highways).

\section{Conclusion}

There is a widespread idea that if a policy generates poverty, that policy is unjust. This idea has been especially prominent in global justice debates, where Pogge and others have claimed that one of the features of the global order that makes it unjust is that it is povertygenerating. Cohen, although critic of Pogge's approach in general, has also defended this view. In this paper I have showed three different things: First, the view that Pogge and Cohen defend is vulnerable to what I call the "skepticisim objection": they both rely on empirical outcomes to condemn rules, but these outcomes are almost impossible to assess in relation to possible alternative outcomes. Second, Pogge is vulnerable to what I call the "normative objection". 
That is, he attempts to draw normative conclusions from facts, but this step is unwarranted. Finally, I have showed that the immorality of sovereign debts does not consist in the fact that a negative outcome follows from a rule, but rather on the internal structure of the agreement that generated the debt. My approach, in contrast to the one that Pogge and Cohen defended, is rather deontological, in the sense that it generated non-binding debts by looking at whether or not duties have been breached, rather than on consequences. 


\section{Notes}

${ }^{1}$ Consejo Nacional de Investigaciones Científicas y Técnicas (CONICET), Universidad de Buenos Aires (UBA), Argentina. E-mail: cdimitriu@hotmail.com

${ }^{2}$ For a summary of Pogge's view, and a description of the Strong Thesis, See Cohen, Joshua (2010). Philosophy, social science, global poverty. In Alison M. Jaggar (ed.), Thomas Pogge and His Critics. Cambridge: Polity Press, page 23

${ }^{3} \mathrm{~A}$ possible reply here is that Pogge relies on the human rights threshold to make the case that the global order is unjust. This is something that he seems to have defended in some of his writings. However, the point that he relies on outcome still applies: the global order would be unjust because it produces suboptimal outcomes, relative to the outcomes it should produce if we take into account the human rights threshold.

${ }^{4}$ Thomas Pogge, "Assisting the Global Poor," in

http://www.princeton.edu/rpds/seminars/pdfs/pogge_assistingpoor.pdf, page 10-15. The emphasis is mine.

${ }^{5}$ Pogge, Thomas. (2005a): Real World Justice. The Journal of Ethics 9 (1-2), 29-53, 49

${ }^{6}$ See Pogge, Thomas (2005): Recognized and violated by international law: the human rights of the global poor. Leiden Journal of International Law 18.4, 717-745

${ }^{7}$ See Cohen Ibid.

${ }^{8}$ Cohen, ibid, page 19

${ }^{9}$ See for example Jayachandran, Seema, Michael Kremer, and S. Shafter (2006): Applying the odious debt doctrine while preserving legitimate lending. Center for International Development https://fsi-live.s3.us-west1.amazonaws.com/s3fs-public/ApplyingtheOdiousDebtsDoctrine.pdf

${ }^{10}$ See Cohen, Ibid, page 40

${ }^{11}$ See Cohen, ibid, page 25

${ }^{12}$ See for example Tan, Kok-Chor (2004): Justice without borders: cosmopolitanism, nationalism, and patriotism. Cambridge: Cambridge University Press. In this book, Tan shows that the view that states have some degree of autonomy is compatible with both cosmopolitanism and statism

${ }^{13} \mathrm{Nili}$, Shmuel (2011): Conceptualizing the curse: two views on our responsibility for the 'resource curse. Ethics \& Global Politics 4.2, 103-124

${ }^{14}$ This is a line of thought that Nicole Hassoun does pursue more explicitly, and that could do the work that Pogge need. See for example Hassoun, Nicole (2016): Individual Responsibility for Promoting Global Health: The Case for a New Kind of Socially Conscious Consumption, The Journal of Law, Medicine \& Ethics Vol 44, Issue 2, 319-331

${ }^{15}$ These conditions have been developed in more detail here. Dimitriu, Cristian (2015): Odious Debts: A Moral Account. Jurisprudence 6.3, 470-491 


\section{References}

Cohen, Joshua (2010). Philosophy, social science, global poverty. In Alison M. Jaggar (ed.), Thomas Pogge and His Critics. Cambridge: Polity Press.

Dimitriu, Cristian (2015): Odious Debts: A Moral Account. Jurisprudence 6.3, 470-491

Hassoun, Nicole (2016): Individual Responsibility for Promoting Global Health: The Case for a New Kind of Socially Conscious Consumption, The Journal of Law, Medicine \& Ethics Vol 44, Issue 2, $319-331$

Jayachandran, Seema, Michael Kremer, and S. Shafter (2006): Applying the odious debt doctrine while preserving legitimate lending. Center for International Development https://fsilive.s3.us-west-1.amazonaws.com/s3fs-public/ApplyingtheOdiousDebtsDoctrine.pdf

Nili, Shmuel (2011): Conceptualizing the curse: two views on our responsibility for the 'resource curse. Ethics \& Global Politics 4.2, 103-124

Pogge, Thomas. (2005a): Real World Justice. The Journal of Ethics 9 (1-2), 29-53

Pogge, Thomas (2005): Recognized and violated by international law: the human rights of the global poor. Leiden Journal of International Law 18.4, 717-745

Pogge, Thomas: Assisting the Global Poor, in http://www.princeton.edu/rpds/seminars/pdfs/pogge assistingpoor.pdf

Tan, Kok-Chor (2004): Justice without borders: cosmopolitanism, nationalism, and patriotism. Cambridge: Cambridge University Press

Wertheimer, Alan (1999): Exploitation. Princeton: Princeton University Press 